\title{
A Survey of OB/GYN Physicians' Training \& Current Practice Patterns in Breast Care
}

To the Editor:

Although it is clear that Ob/Gyns need education in care of the breast, specific training during residency in this area is highly varied. The core competencies described by the residency review committee (RRC) requirements mandate some fundamental core skills in breast management, but there are many gaps in expected experiences (1). This is surprising, not only because delayed or missed breast cancer diagnosis is a significant problem in US but because office-based breast procedures are typically quite straight-forward, particularly for a surgical specialty like Ob/Gyn. We conducted a survey of the practice patterns related to breast disease and the extent of residency training in breast care in a nationally representative sample of Ob/Gyns.

A total of 400 ACOG fellows and junior fellows, who were members of the collaborative ambulatory research network (CARN) were invited to participate. CARN is a representative group of practicing US Ob/ Gyns (ACOG members) who volunteer to participate in periodic surveys. Demographic and current practice setting information were collected as well as the answers to 35 questions about breast care practices and their residency training in breast care.

Data were analyzed using SPSS version 16.0. Chisquared and $t$-tests were used to compare responses as appropriate. IRB approval for this survey was obtained through American University on July 14, 2009.

Of the 400 physicians who received the survey, three were ineligible, and 241 responded $(241 / 397=$ $60.7 \%)$. The mean age was 51.1 years $(\mathrm{SD}=10.3)$, $52.1 \%$ were female physicians. Male respondents were

Address correspondence reprint requests to: Mark Pearlman, MD, Department of Obstetrics \& Gynecology, 1500 E Medical Center Dr., L4000 Women's Hospital, Ann Arbor, MI 48109-5276, USA, or e-mail: pearlman@med.umich.edu.

DOI: $10.1111 /$ tbj.12028

(C) 2012 Wiley Periodicals, Inc., 1075-122X/12

The Breast Journal, Volume 18 Number 6, 2012 634-636 older than female respondents (M: 56.1 years versus F: $46.6 ; \mathrm{p}<.001)$. Table 1 describes breast-related practice patterns. $84 \%$ answered yes to "do you perceive yourself as a provider of breast care for your patients?" Those who do not regard themselves as providers of breast care still perform breast cancer screening and see patients with breast complaints, although at lower rates. Those who do perceive themselves as breast care providers perform about 40 breast cancer screenings/week, and see five patients with breast complaints/week; those who do not perceive themselves as providers of breast care perform 18 breast cancer screenings/week and see two women with breast complaints/week. Respondents reported very limited use of procedures in the management and/or diagnosis of breast disease (Table 1).

Only one third of Ob/Gyns reported receiving specific training in breast care management during residency. The presence or absence of residency training in breast care had no significant impact on self-perception as a breast care provider, the frequency of breast cancer screenings, or the number of patients with breast complaints seen. Of the 82 respondents trained in breast care as residents, one third were trained by $\mathrm{Ob} / \mathrm{Gyn}$ physicians, and the remaining two-thirds were trained by non-Ob/Gyn surgeons or "others" (not specified). The respondents also reported that the amount of training varied by the specialty of the physician-educator, with significantly more half days of training reported by those instructed by $\mathrm{Ob} / \mathrm{Gyn}$ physicians.

Those who reported being trained by Ob/Gyn educators are significantly older, and have been in practice significantly longer than those trained by nonOb/Gyn physician educators (50.8 years versus 43.9; $\mathrm{p}=.005)$, suggesting that current training in breast care is increasingly done by those who are not $\mathrm{Ob} /$ Gyn physicians. Those with no training and those trained by non-Ob/Gyn physicians were also more likely to report "a lack of training in the management 
Table 1. Breast Care Practice Patterns of Surveyed Ob/Gyn Physicians

\begin{tabular}{|c|c|}
\hline Breast care/breast cancer screening & $\begin{array}{l}\text { Answer: Yes }(\% \text {, } \\
95 \% \mathrm{Cl})\end{array}$ \\
\hline $\begin{array}{l}\text { Do you perceive yourself as a provider of breast } \\
\text { care for your patients? }\end{array}$ & $84[79.3-88.7]$ \\
\hline $\begin{array}{l}\text { In general, do the majority of your colleagues in your } \\
\text { Ob/Gyn practice perceive themselves to be } \\
\text { providers of breast care for their patients? }\end{array}$ & $92[88.1-95.9]$ \\
\hline $\begin{array}{l}\text { Do you consider breast cancer screening to be part } \\
\text { of your usual practice? }\end{array}$ & $96[93.4-98.6]$ \\
\hline Patients seen per week & Mean (SE) \\
\hline Total number & $85.2(2.6)$ \\
\hline Screened for breast cancer & $36.9(1.7)$ \\
\hline Presenting with breast complaints & $4.3(4.3)$ \\
\hline Do you perform this procedure? & $\begin{array}{l}\text { Answer "Yes", (\%, } \\
95 \% \mathrm{Cl})\end{array}$ \\
\hline Cyst fluid aspiration & $46[43-49]$ \\
\hline Fine needle aspiration for cytology & $15[10.5-19.5]$ \\
\hline Core biopsy & $1[0-2.4]$ \\
\hline Excisional biopsy & $1[0-2.2]$ \\
\hline Wire localization excisional biopsy & $1[0-2.2]$ \\
\hline How often do you treat? & $\begin{array}{l}\text { Answer "NEVER" } \\
(\%, 95 \mathrm{Cl})\end{array}$ \\
\hline Pain & $4(1.4-6.6)$ \\
\hline Mass & $37(30.9-43.1)$ \\
\hline Abnormal breast imaging & $51(43.5-57.5)$ \\
\hline High risk for breast cancer & $26(20.3-31.7)$ \\
\hline Nipple discharge & $12(7.9-16.1)$ \\
\hline Breast inflammation (e.g., mastitis) & $3(0.8-5.2)$ \\
\hline
\end{tabular}

of breast disease" to be a barrier to providing care of the breast.

However, $81.7 \%$ of those who answered yes to "not being adequately trained for the management of breast disease is a barrier to my provision of breast care" still perceive themselves as breast care providers. Among those surveyed who are "providers of breast care", $83 \%$ indicated they wanted to keep the same volume of breast care practice, $12 \%$ wanted to do more, and only $5 \%$ wanted to do less breast care.

This survey suggests that $\mathrm{Ob} / \mathrm{Gyn}$ physicians play a large role in breast cancer screening and the management of breast complaints. Ob/Gyn physicians value this role, as the majority $(95 \%)$ indicates that they desire to provide the same amount or more services in the area of breast care. Interestingly, the majority of Ob/Gyn physicians report that residency training inadequately prepared them to serve in this capacity. Further suggestion of inadequate training lies in data from the physician insurance association of America, which reports that $\mathrm{Ob} / \mathrm{Gyn}$ physicians are the most frequently sued specialty (outside of radiology) for delayed diagnosis of breast cancer (2).

A minority of physicians surveyed reported performing even simple office-based diagnostic procedures, procedures that $\mathrm{Ob} / \mathrm{Gyn}$ surgeons should be able to easily master easily if exposed to them in their training. Given the high incidence of breast cancer and the malpractice experience in this clinical area, we believe these data provide impetus for $\mathrm{Ob} /$ Gyn residency programs to improve the quality/quantity of training $\mathrm{Ob} / \mathrm{Gyn}$ physicians in these diagnostic procedures.

The council on resident education in obstetrics and gynecology (CREOG) educational objectives 2009 includes the topics of breast cancer screening, benign breast disorders, breast cancer diagnosis and management, breast procedures, and imaging (1). Our data suggest that these objectives were not routinely taught during residencies of those surveyed. We believe that the RRC for Ob/Gyn should provide increased standardization of the expectations and experience in breast training during residency.

The traditional model for breast management is a woman with breast complaints or in need of breast screening who typically presents to their Ob/Gyn (or $\mathrm{PCP}$ ). Breast imaging is ordered, the radiologist performs imaging then refers the patient back to the $\mathrm{Ob} /$ Gyn. If the work-up requires histology/cytology, the patient is referred to a general surgeon for diagnostic testing, and if benign, referred back to the Ob/Gyn for on-going management or surveillance. If cancer, surgical care would then be provided by the surgeon and then the patient would be referred to a variety of other breast cancer providers. The authors observe that in many practices, the flow of patients with breast diseases/screening has already changed. Patients with a breast complaint or in need of breast screening and are referred by their Ob/Gyn to breast imaging. Abnormal breast imaging requiring biopsy is usually done in radiology (image-guided core biopsy). If the results are benign, they are sent back to their $\mathrm{Ob} / \mathrm{Gyn}$ for ongoing management/surveillance. If breast cancer is detected, they are referred to a breast cancer center with all breast cancer services incorporated into a single multidisciplinary service (3). In this newer model, the radiologist provides the technical services to obtain necessary imaging and biopsy material, but the $\mathrm{Ob} / \mathrm{Gyn}$ (or other primary provider) directs the workup and management, including any additional diagnostic testing required. This newer strategy is preferable because it allows improved patient continuity by placing responsibility for both diagnostic and management decisions with a single trained provider. Of course, designated breast centers 
are an outstanding model for management of breast diseases and should be used where available. However, because breast centers do not exist in many communities, Ob/Gyn physicians (and primary care providers) should be trained to manage common breast problems. Complex breast problems and breast cancer should be referred to properly trained specialists.

This emerging model requires adequately trained $\mathrm{Ob} / \mathrm{Gyn}$ practitioners. We believe that expanding and improving existing training for $\mathrm{Ob} / \mathrm{Gyn}$ physicians in breast disease management would likely enhance the quality of breast care. Although this survey did not address the extent or influence of continuing medical education programs, a previous study of CME and postgraduate training in the management of breast masses showed no significant change in physician behavior after completing the training program (4). Identifying and creating expert clinical educators in breast diseases within the $\mathrm{Ob} /$ Gyn specialty and the development of novel educational tools to supplement currently available resources will be necessary to improve the quality of breast care for women.

\section{Acknowledgments}

This study was supported in part by grant \#R60 MC 05674 from the Maternal and Child Health Bureau, Health Resources and Services Administration, Department of Health and Human Services.

\section{DISCLOSURE}

None of the authors have a conflict of interest.
Mark D. Pearlman, MD* Britta S. Anderson, MA, PhD Ann V. Bell, MA, $\mathrm{PhD}^{\ddagger}$ Jennifer L. Griffin, MD, $\mathrm{MPH}^{\S}$ Jay Shulkin, $\mathrm{PhD}^{9}$ Raymond De Vries, PhD

*Department of Obstetrics \& Gynecology Director, Breast Fellowship in Ob/Gyn University of Michigan Medical School, Ann Arbor, MI;

${ }^{\dagger}$ Department of Medical Education University of Michigan Medical School, Ann Arbor, MI;

tDepartment of Sociology University of Michigan, Ann Arbor, MI; ${ }^{\S}$ Department of Obstetrics \& Gynecology University of Nebraska Medical Center Omaha, Omaha, NE; and ${ }^{\natural}$ American College of Obstetricians and Gynecologists, Washington, DC

\section{REFERENCES}

1. CREOG. A Core Curriculum in Obstetrics and Gynecology, 9th edn. Washington, DC: Council on Resident Education in Obstetrics and Gynecology, 2009.

2. PIAA. Breast Cancer Study, 3rd edn. Rockville, MD: Physician Insurers Association of America, 2002.

3. Newman LE, Guest A, Helvie M, et al. Changes in surgical management resulting from case review at a breast cancer multidisciplinary tumor board. Cancer 2006;107:2346-51.

4. Price DW, Xu S, McClure D. Effect of CME on Primary Care and Ob/Gyn Treatment of Breast Masses. J Contin Educ Health Prof 2005;25:240-247. 